\title{
High mitochondria content is associated with prostate cancer disease progression
}

\author{
Katharina Grupp ${ }^{1,2 \dagger}$, Karolina Jedrzejewska ${ }^{2 \dagger}$, Maria Christina Tsourlakis ${ }^{2 *}$, Christina Koop ${ }^{2}$, Waldemar Wilczak², \\ Meike Adam ${ }^{3,4}$, Alexander Quaas², Guido Sauter ${ }^{2}$, Ronald Simon², Jakob Robert Izbicki ${ }^{1}$, Markus Graefen ${ }^{3}$, \\ Hartwig Huland ${ }^{3}$, Thorsten Schlomm ${ }^{3,4}$, Sarah Minner ${ }^{2}$ and Stefan Steurer ${ }^{2}$
}

\begin{abstract}
Background: Mitochondria are suggested to be important organelles for cancer initiation and promotion. This study was designed to evaluate the prognostic value of MTC02, a marker for mitochondrial content, in prostate cancer.

Methods: Immunohistochemistry of using an antibody against MTC02 was performed on a tissue microarray (TMA) containing 11,152 prostate cancer specimens. Results were compared to histological phenotype, biochemical recurrence, ERG status and other genomic deletions by using our TMA attached molecular information.

Results: Tumor cells showed stronger MTC02 expression than normal prostate epithelium. MTC02 immunostaining was found in $96.5 \%$ of 8,412 analyzable prostate cancers, including $15.4 \%$ tumors with weak, $34.6 \%$ with moderate, and $46.5 \%$ with strong expression. MTC02 expression was associated with advanced pathological tumor stage, high Gleason score, nodal metastases ( $p<0.0001$ each), positive surgical margins $(p=0.0005)$, and early PSA recurrence $(p<0.0001)$ if all cancers were jointly analyzed. Tumors harboring ERG fusion showed higher expression levels than those without $(p<0.0001)$. In ERG negative prostate cancers, strong MTC02 immunostaining was linked to deletions of PTEN, 6q15, 5q21, and early biochemical recurrence ( $p<0.0001$ each). Moreover, multiple scenarios of multivariate analyses suggested an independent association of MTCO2 with prognosis in preoperative settings.

Conclusions: Our study demonstrates high-level MTC02 expression in ERG negative prostate cancers harboring deletions of PTEN, 6q15, and 5q21. Additionally, increased MTC02 expression is a strong predictor of poor clinical outcome in ERG negative cancers, highlighting a potentially important role of elevated mitochondrial content for prostate cancer cell biology.
\end{abstract}

Keywords: MTC02, ERG, Prostate cancer, Tissue microarray

\section{Background}

Prostate cancer is a major cause of cancer-related mortality and morbidity in males [1]. Although the majority of prostate cancers present as low malignant, indolent tumors, there is also an aggressive subset. For example in Germany, about 60,000 new cases of prostate cancer are diagnosed every year, and still about 11,000 patients die from their disease [2]. The common pre-operative parameters including Gleason grade, tumor extent in

\footnotetext{
* Correspondence: mtsourlakis@uke.de

${ }^{\dagger}$ Equal contributors

${ }^{2}$ Institute of Pathology, University Medical Center Hamburg-Eppendorf, Martinistr. 52, 20246 Hamburg, Germany

Full list of author information is available at the end of the article
}

biopsies, and preoperative prostate specific antigen (PSA) levels are statistically powerful prognosticators, however insufficient to allow for optimal treatment decisions in individual patients. Accordingly, there is a considerable need for improved diagnostic tools to early distinguish these patients requiring aggressive therapy with all its associated side effects from the majority of patients who will not. It is hoped, that advances in basic prostate cancer research will eventually lead to novel prognostic biomarkers and better therapeutic options.

The growing interest in mitochondrial function and dysfunction reflects the potential role of mitochondria for cancer development [3]. Loss of proliferation control in cancer cells eventually results in cellular bulks that 
extend beyond the capacity of their vasculature, resulting in oxygen and nutrient deprivation. Accordingly, tumor growth is accompanied by cellular adaptations to overcome these limitations. Mitochondria are key organelles for energy production including glucose metabolism and oxidative phosphorylation with a critical role in cell survival and apoptosis. Amount and activity of mitochondria may hence play a critical role in tumor initiation and progression [4], and it is not surprising that mutations of mitochondrial genes or alterations of the mitochondrial content have been suggested to play an important role in various cancer types [5-8]. As a consequence, an increasing number of anti-cancer drugs is under development [9-11] targeting mitochondria and associated structures. Some studies have even suggested that intracellular accumulation of mitochondria (the socalled mitochondrion-rich phenotype) might represent an important adaptive mechanism in rectal and breast cancer $[12,13]$.

Mutations of mitochondrial DNA were also identified in prostate cancer [14-22] and deregulated mitochondrial metabolism has been suggested to play a relevant role in prostate carcinogenesis [23-25]. Based on these reports, we hypothesized that also the quantity of mitochondria present in prostate cancer cells might be of clinical relevance, and that the cellular mitochondria content might vary between prostate cancer subgroups harboring different key molecular alterations that might influence cell metabolism.

The antibody MTC02 (mouse monoclonal to mitochondria) recognizes a $60 \mathrm{kDa}$ non glycosylated protein component of mitochondria found in human cells, and has been used to determine the mitochondrial content of tumor cells in a variety of previous studies. For example, earlier studies used MTC02 to determine the molecular genetic alterations [13] and the frequency, morphology and clinical features of mitochondrion-rich breast cancers [26]. A tissue microarray (TMA) containing 11,152 prostate cancer specimens with clinical follow-up information and an attached molecular database was analyzed in order to evaluate the clinical significance of mitochondria content, and to search for possible associations with molecularly defined cancer subgroups. Our study demonstrates that "mitochondrionrich phenotype" is strongly associated with molecular cancer features and strongly linked to poor prognosis in ERG negative prostate cancers.

\section{Materials and methods Patients}

Radical prostatectomy specimens were available from 11,152 patients, undergoing surgery between 1992 and 2011 at the Department of Urology, and the Martini Clinics at the University Medical Center Hamburg-Eppendorf.
Research using pseudomized human left-over tissue samples from routine diagnosis was performed in compliance with the Helsinki Declaration, and is covered by $\$ 12$ of the Hamburgisches Krankenhausgesetz (HmbKHG). Manufacturing and usage of tissue microarrays for research purposes has been has been approved by the Institutional Review Board of the Aerztekammer Hamburg (Chair: Prof. T. Weber, Ref. WF-049/09). Follow-up data were available of 9,695 patients with a median follow-up of 36.8 months (range: 1 to 228 months; Table 1). Prostate specific antigen values were measured following surgery and recurrence was defined as a postoperative PSA of $0.2 \mathrm{ng} / \mathrm{ml}$ and increasing at first of appearance. All prostate specimens were analyzed according to a standard procedure, including complete embedding of the entire prostate for histological analysis [27]. The TMA manufacturing process was described earlier in detail [28]. In short, one $0.6 \mathrm{~mm}$ core was taken from a representative tissue block from each patient. The tissues were distributed among 24 TMA blocks, each containing 144 to 522 tumor samples. Presence or absence of cancer tissue was validated by immunohistochemical AMACR and 34BE12 analysis on adjacent TMA sections. For internal controls, each TMA block also contained various control tissues, including normal prostate tissue. The molecular database attached to this TMA contained results on ERG expression in 9,628, ERG break apart fluorescence in-situ hybridization (FISH) analysis in 6,106 (expanded from [29]), and deletion status of 5q21 in 3,037 [30], 6q15 in 3,528 (extended from [31]), PTEN in 6,130 [32] and 3p13 in 1,290 tumors (unpublished data) tumors.

\section{Immunohistochemistry}

Freshly cut TMA sections were analyzed in one day and in one experiment. Slides were deparaffinized and exposed to heat-induced antigen retrieval for 5 minutes in an autoclave at $121^{\circ} \mathrm{C}$ in $\mathrm{pH} 7.8$ Tris-EDTA-Citrate buffer prior to incubation with antibody MTC02 (Abcam; $1 / 450$ dilution) detecting a nonglycolizated mitochondrial protein of $60 \mathrm{KD}$. Bound antibody was visualized using the EnVision Kit (Dako). MTC02 staining was homogenous in the analyzed tissue samples and staining intensity of all cases was semiquantitatively assessed in four categories: negative, weak, moderate and strong immunostaining.

\section{Statistics}

Statistical calculations were performed with JPM 9 software (SAS Institute Inc., NC, USA). Contingency tables and the $\mathrm{chi}^{2}$-test were performed to search for associations between molecular parameters and tumor phenotype. Survival curves were calculated according to KaplanMeier. The Log-Rank test was applied to detect significant differences between groups. COX proportional hazards 
Table 1 Composition of the prognostic tissue microarray containing 11,152 prostate cancer specimens

\begin{tabular}{|c|c|c|}
\hline & \multicolumn{2}{|c|}{ No. of patients } \\
\hline & $\begin{array}{c}\text { Study cohort } \\
\text { on tissue microarray } \\
(n=11,152)\end{array}$ & $\begin{array}{c}\text { Biochemical } \\
\text { relapse among } \\
\text { categories }(n=1,824)\end{array}$ \\
\hline \multicolumn{3}{|c|}{ Follow-up (mo) } \\
\hline Mean & 53.4 & \\
\hline Median & 36.8 & \\
\hline \multicolumn{3}{|l|}{ Age (y) } \\
\hline$<50$ & 318 & 49 \\
\hline $50-60$ & 2.77 & 460 \\
\hline $60-70$ & 6.55 & 1.08 \\
\hline$>70$ & 1.44 & 232 \\
\hline \multicolumn{3}{|c|}{$\begin{array}{l}\text { Pretreatment } \\
\text { PSA (ng/ml) }\end{array}$} \\
\hline$<4$ & 1.41 & 142 \\
\hline $4-10$ & 6,735 & 827 \\
\hline $10-20$ & 2,159 & 521 \\
\hline$>20$ & 720 & 309 \\
\hline \multicolumn{3}{|c|}{$\begin{array}{l}\text { pT category } \\
\text { (AJCC 2002) }\end{array}$} \\
\hline pT2 & 7.370 & 570 \\
\hline рT3a & 2.41 & 587 \\
\hline pT3b & 1.26 & 618 \\
\hline pT4 & 63 & 49 \\
\hline \multicolumn{3}{|c|}{ Gleason grade } \\
\hline$\leq 3+3$ & 2.86 & 193 \\
\hline $3+4$ & 1.57 & 573 \\
\hline $4+3$ & 6.18 & 849 \\
\hline$\geq 4+4$ & 482 & 208 \\
\hline \multicolumn{3}{|c|}{ pN category } \\
\hline pNO & 6.12 & 1.13 \\
\hline $\mathrm{pN}+$ & 561 & 291 \\
\hline \multicolumn{3}{|c|}{ Surgical margin } \\
\hline Negative & 8.98 & 1.15 \\
\hline Positive & 1.970 & 642 \\
\hline
\end{tabular}

NOTE: Numbers do not always add up to 11,152 in the different categories because of cases with missing data. Abbreviation: AJCC American Joint Committee on Cancer.

regression analysis was performed to test the statistical independence and significance between pathological, molecular and clinical variables.

\section{Results}

\section{Technical issues}

A total of 2,744 of $11,152(24.6 \%)$ tissue spots were noninformative for MTC02 immunohistochemistry due to the complete lack of tissue or absence of unequivocal cancer cells on the respective TMA spots.

\section{MTC02 immunohistochemistry}

MTC02 immunostaining was located in the cytoplasm of prostate cells. Cancer cells showed higher staining intensities as compared to normal prostate glands. No differences in the staining patter of the different prostate cancer subtypes were observed. In prostate cancer, MTC02 immunostaining was found in $96.5 \%$ of the 8,412 analyzable prostate cancers and was considered strong in $46.5 \%$, moderate in $34.6 \%$ and weak in $15.4 \%$ of tumors. Representative images demonstrating MTC02 expression in prostate cancer tissue are given in Figure 1. Strong MTC02 staining was associated with advanced pathological tumor stage, high Gleason grade, positive nodal involvement $(p<0.0001$ each), positive surgical margin $(p=0.0005)$, and early PSA recurrence if all cancers were jointly analyzed $(p<0.0001)$.

\section{Association to cell proliferation}

In order to study the impact of mitochondrial content on cell proliferation, we compared MTC02 data with immunohistochemical Ki67 expression that was available from a previous study [33]. We found a strong positive association of MTC02 with Ki67 label index $(p<0.0001)$.

\section{Association with fusion type prostate cancer}

To determine whether the mitochondrial content is linked to fusion type prostate cancer, we compared MTC02 staining with the ERG-fusion status (obtained by FISH and IHC in 4,818 and 7,500 tumors with MTC02 data) available from our database. Strong MTC02 immunostaining was slightly more prevalent in ERG fusion positive prostate cancers, regardless if the $E R G$ status was obtained by IHC or FISH analysis $(p<0.0001$ each; Figure 2). Based on these data, associations with tumor phenotype and clinical cancer features were separately analyzed in the subsets of ERG positive and negative prostate cancers (Tables 2/3). In 4,151 ERG negative cancers, strong MTC02 staining was significantly associated with high preoperative PSA-levels $(p=0.0372)$, advanced pathological tumor stage, high Gleason grade, positive nodal involvement and positive surgical margin status $(p<0.0001$ each; Table 2). In 3,349 ERG positive prostate cancers, these associations were largely inexistent, although there was still a weak association between MTC02 staining and high Gleason grade $(p=0.008$; Table 3).

Relationship with key genomic deletions associated with distinct subgroups of prostate cancers

Earlier studies had provided evidence for distinct molecular subgroups of prostate cancers defined by fusion status and several genomic deletions. Others and us had described strong associations between deletions of PTEN and 3p13 and ERG positive cancers and between 


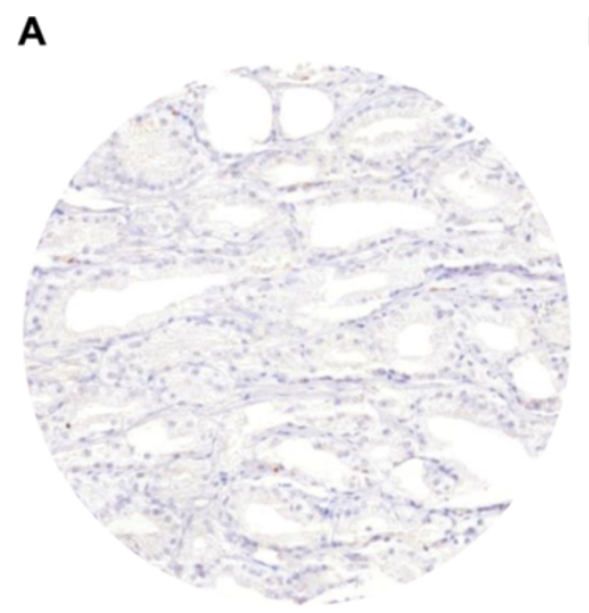

C

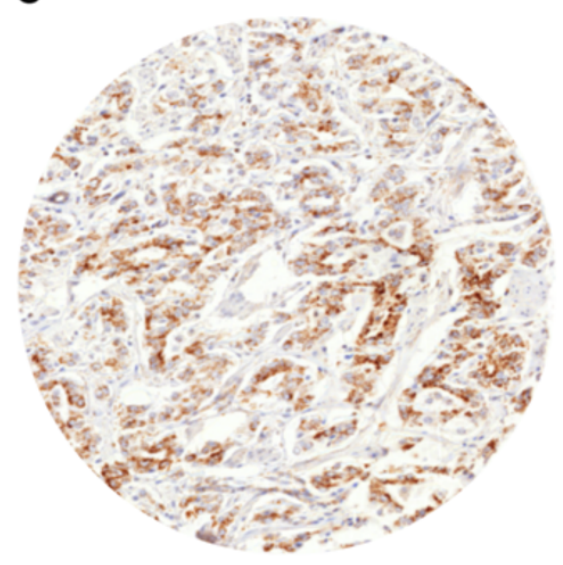

B

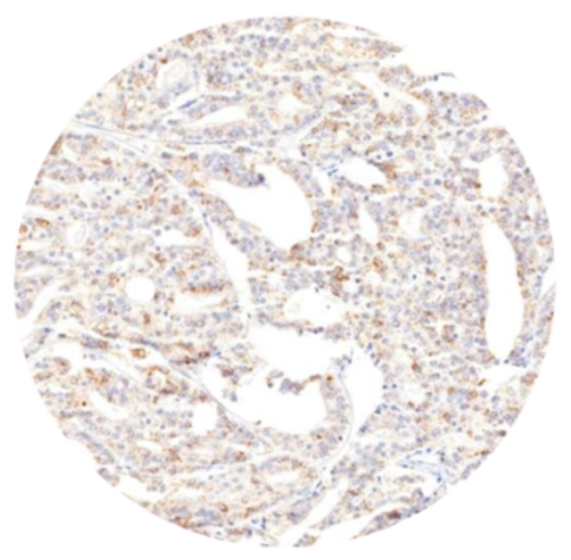

D

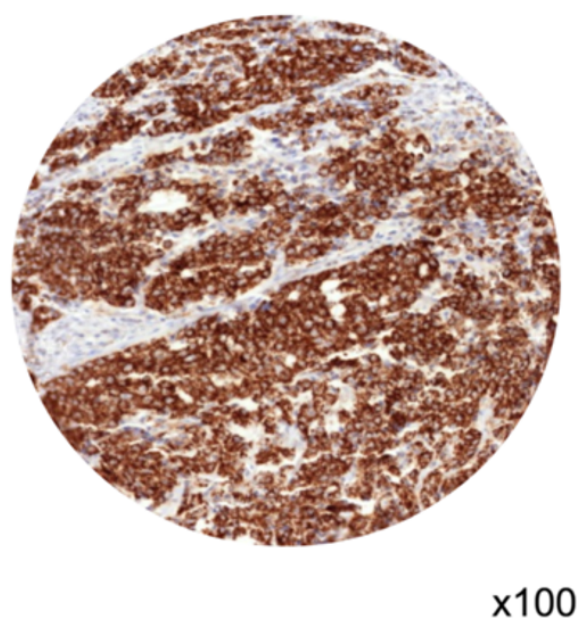

Figure 1 Representative pictures of (A) negative, (B) weak, (C) moderate, and (D) strong MTC02 immunostaining in prostate cancer.

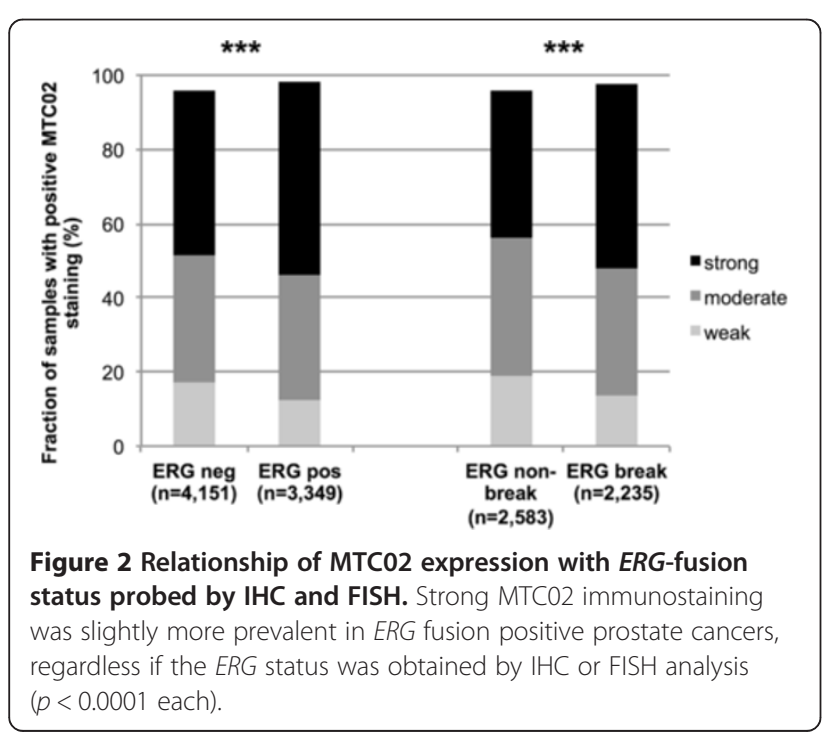

deletions of 5q21 and 6q15 and ERG negative tumors [30-32,34-36]. To study, whether or not some of these subgroups may have a particularly high mitochondrial content, MTC02 immunostaining was compared with preexisting deletion results. Interestingly, mitochondrial content was largely unrelated to all analyzed chromosomal deletions if all tumors were analyzed (Figure $3 \mathrm{~A}$ ) while there were reciprocal statistically significant findings in the subgroups of ERG positive and ERG negative cancers. In ERG negative cancers, most deletions (PTEN, 5q, 6q; $p<0.0001$ each; Figure 3B) were significantly associated with high mitochondrial content, while there was a tendency towards lower mitochondrial content in ERG positive cancers harboring deletions (Figure 3C). This tendency did, however, reach significance only for deletions of PTEN $(p=0.0004)$ and $5 q(p=0.0408)$.

\section{Prognostic impact}

Follow-up data were available from 7,402 patients with data on mitochondrial content. The prognostic role of 
Table 2 Associations between MTC02 expression results and ERG negative prostate cancer phenotype

\begin{tabular}{|c|c|c|c|c|c|c|}
\hline \multirow[b]{2}{*}{ Parameter } & \multirow[b]{2}{*}{ n evaluable } & \multicolumn{4}{|c|}{ МСТ02 IHC result } & \multirow[b]{2}{*}{$p$ value } \\
\hline & & Negative (\%) & Weak (\%) & Moderate (\%) & Strong (\%) & \\
\hline All cancers & 4.15 & 4.2 & 17.1 & 34.2 & 44.5 & \\
\hline \multicolumn{7}{|c|}{ PSA preoperative } \\
\hline$<4$ & 423 & 4.02 & 18.2 & 33.57 & 44.21 & 0.0372 \\
\hline $4-10$ & 2.43 & 3.88 & 17.94 & 35.42 & 42.76 & \\
\hline $10-20$ & 925 & 5.08 & 16.11 & 32.76 & 46.05 & \\
\hline$>20$ & 337 & 3.56 & 12.76 & 31.16 & 52.52 & \\
\hline \multicolumn{7}{|c|}{ Tumor stage } \\
\hline pT2 & 2.74 & 4.42 & 20.02 & 36.24 & 39.31 & $<0.0001$ \\
\hline рT3a & 859 & 4.07 & 13.62 & 32.83 & 49.48 & \\
\hline pT3b & 515 & 3.3 & 8.16 & 25.83 & 62.72 & \\
\hline pT4 & 26 & 0 & 7.69 & 30.77 & 61.54 & \\
\hline \multicolumn{7}{|c|}{ Gleason grade } \\
\hline$\leq 3+3$ & 906 & 6.62 & 25.17 & 38.19 & 30.0 & $<0.0001$ \\
\hline $3+4$ & 2.32 & 3.67 & 17.02 & 36.29 & 43.02 & \\
\hline $4+3$ & 685 & 3.5 & 11.09 & 26.86 & 58.54 & \\
\hline$\geq 4+4$ & 226 & 1.77 & 3.98 & 19.91 & 74.34 & \\
\hline \multicolumn{7}{|c|}{ Lymph node metastasis } \\
\hline NO & 2.41 & 4.28 & 16.09 & 33.85 & 45.78 & $<0.0001$ \\
\hline $\mathrm{N}+$ & 230 & 3.04 & 6.52 & 23.04 & 67.39 & \\
\hline \multicolumn{7}{|c|}{ Surgical margin } \\
\hline Negative & 3.29 & 4.01 & 18.09 & 35.2 & 42.71 & $<0.0001$ \\
\hline Positive & 783 & 4.34 & 13.28 & 29.89 & 52.49 & \\
\hline
\end{tabular}

Gleason grade was plotted for this patient cohort in order to demonstrate the overall validity of our followup data $(p<0.0001$; Figure 4 A). High MTC02 immunostaining was related to early biochemical recurrence if all cancers were analyzed ( $p<0.0001$; Figure 4B). A subset analysis revealed, that this association was purely driven by ERG negative cancers $(p<0.0001$; Figure 4 C) while the mitochondrial content was unrelated to PSA recurrence in ERG positive cancers ( $p=0.7598$, Figure 4D). A refined analysis further revealed that the prognostic relevance of MTC02 was limited the 1,852 ERG-negative cancers lacking PTEN deletion ( $p<0.0001$; Figure $4 \mathrm{E})$, while there was no effect in 249 ERG negative cancers harboring PTEN deletions ( $p=0.2367$; Figure 4F).

\section{Multivariate analysis}

Four multivariate analyses were performed evaluating the clinical relevance of MTC02 immunostaining in different scenarios (Table 4A-C). Analysis \#1 employed all post-operatively available parameters including $\mathrm{pT}$, $\mathrm{pN}$, margin status, pre-operative PSA value and Gleason grade obtained on the resected prostate. Scenario \#2 included all postoperatively available parameters with the exception of nodal status. The rational for this approach was that lymphadenectomy is not a routine procedure in the surgical therapy of prostate cancer and that excluding $\mathrm{pN}$ in multivariate analysis increases case numbers. The remaining two scenarios tried to better model the preoperative situation. Scenario \#3 included the mitochondrial content, pre-operative PSA, clinical stage (cT) and the Gleason grade obtained on the prostatectomy specimen. Because the post-operative Gleason grade varies from the pre-operative Gleason grade, another multivariate analysis (\#4) was added. In scenario \#4, the preoperative Gleason grade obtained on the original biopsy was combined with pre-operative PSA, clinical stage and MTC02 staining. The diverse multivariate analyses suggest a possible independent prognostic impact of MTC02 immunostaining in a preoperative setting, especially in ERG negative cancers (Table 4).

\section{Discussion}

The results of our study show, that the mitochondria content is tightly linked to various pathological, molecular features of prostate cancer. This data highlight the prominent importance of mitochondrial function for prostate cancer development and progression. 
Table 3 Associations between MTC02 expression results and ERG positive prostate cancer phenotype

\begin{tabular}{|c|c|c|c|c|c|c|}
\hline \multirow[b]{2}{*}{ Parameter } & \multirow[b]{2}{*}{$\mathrm{n}$ evaluable } & \multicolumn{4}{|c|}{ МСТ02 IHC result } & \multirow[b]{2}{*}{$\mathrm{p}$ value } \\
\hline & & Negative (\%) & Weak (\%) & Moderate (\%) & Strong (\%) & \\
\hline All cancers & 3.35 & 1.8 & 12.2 & 33.8 & 52.2 & \\
\hline \multicolumn{7}{|c|}{ PSA preoperative } \\
\hline$<4$ & 451 & 2.66 & 11.97 & 32.59 & 52.77 & 0.9613 \\
\hline $4-10$ & 2.03 & 1.73 & 12.03 & 34.12 & 52.12 & \\
\hline $10-20$ & 604 & 1.66 & 12.75 & 33.44 & 52.15 & \\
\hline$>20$ & 218 & 1.83 & 13.3 & 35.78 & 49.08 & \\
\hline \multicolumn{7}{|c|}{ Tumor stage } \\
\hline pT2 & 1.980 & 1.92 & 11.31 & 34.55 & 52.22 & 0.5463 \\
\hline рT3a & 902 & 1.77 & 13.86 & 33.81 & 50.55 & \\
\hline pT3b & 427 & 1.64 & 12.41 & 30.68 & 55.27 & \\
\hline pT4 & 22 & 0 & 18.18 & 36.36 & 45.45 & \\
\hline \multicolumn{7}{|c|}{ Gleason grade } \\
\hline$\leq 3+3$ & 745 & 3.36 & 10.07 & 36.64 & 49.93 & 0.008 \\
\hline $3+4$ & 1.98 & 1.26 & 12.32 & 33.01 & 53.41 & \\
\hline $4+3$ & 485 & 2.06 & 14.85 & 33.81 & 49.28 & \\
\hline$\geq 4+4$ & 114 & 0.88 & 13.16 & 32.46 & 53.51 & \\
\hline \multicolumn{7}{|c|}{ Lymph node metastasis } \\
\hline NO & 1.9 & 1.63 & 12.2 & 34.56 & 51.6 & 0.7185 \\
\hline $\mathrm{N}+$ & 192 & 1.04 & 14.58 & 32.81 & 51.56 & \\
\hline \multicolumn{7}{|c|}{ Surgical margin } \\
\hline Negative & 2.62 & 1.83 & 12.48 & 33.73 & 51.96 & 0.825 \\
\hline Positive & 670 & 1.94 & 11.19 & 34.63 & 52.24 & \\
\hline
\end{tabular}

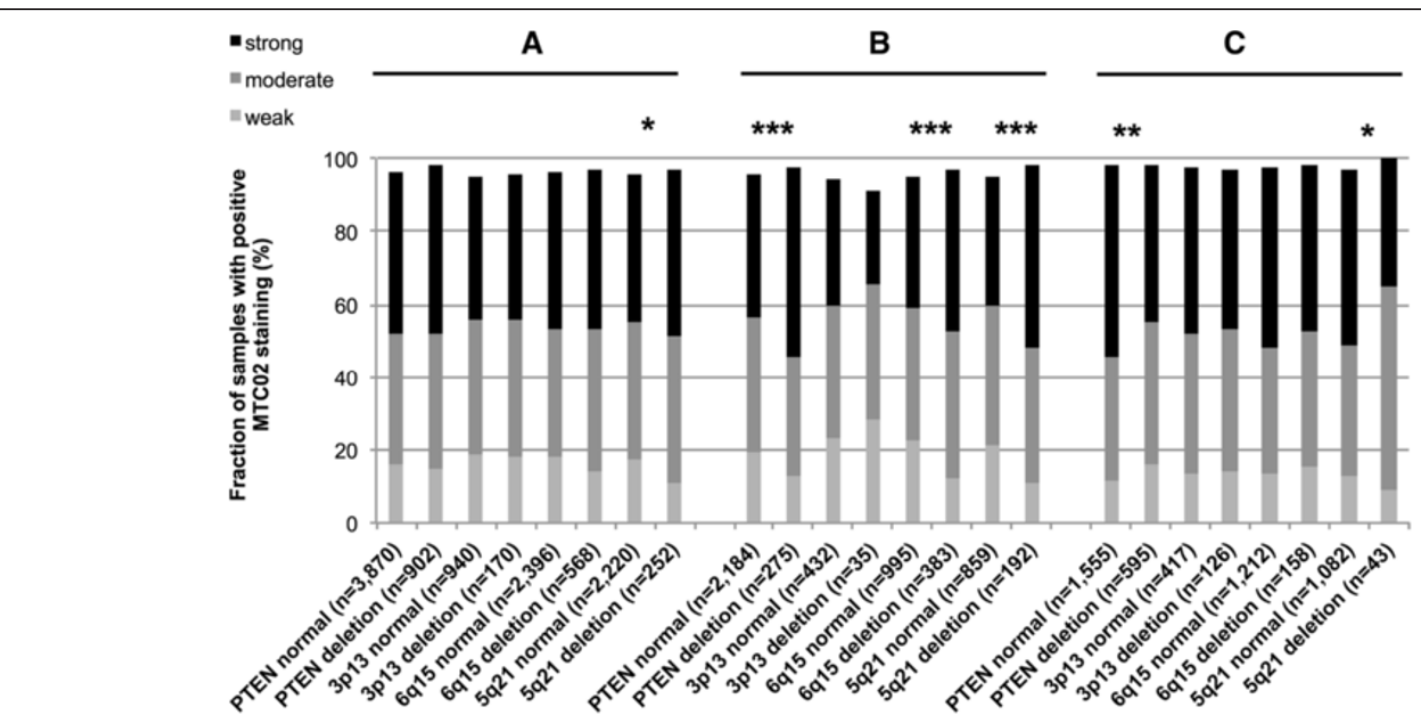

Figure 3 Relationship between MTC02 expression and deletions of PTEN, 3p13, 6q15 and 5q21 probed by FISH analysis. (A) Association between MTC02 expression and deletions of PTEN $(p=0.0596), 3 p 13(p=0.0989), 6 q 15(p=0.0867)$ and $5 q 21\left({ }^{*} p=0.0253\right)$ in all prostate cancers. Relationship of MTC02 expression with (B) deletions of PTEN (*** $p<0.0001), 3 p 13(p=0.641), 6 q 15\left({ }^{* *} p<0.0001\right)$ and $5 q 21(* * * p 0.0001)$ in the subset of ERG negative prostate cancers and with $(\mathbf{C})$ deletions of PTEN (** $p=0.0004), 3 p 13(p=0.9491), 6 q 15(p=0.7544)$ and $5 q 21$ $\left({ }^{*} p=0.0408\right)$ in the subset of ERG positive cancers. 


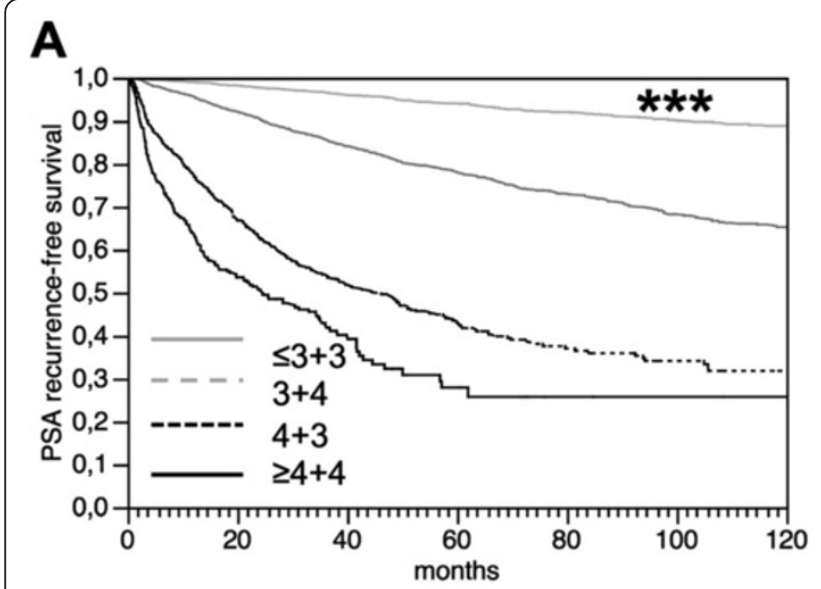

C

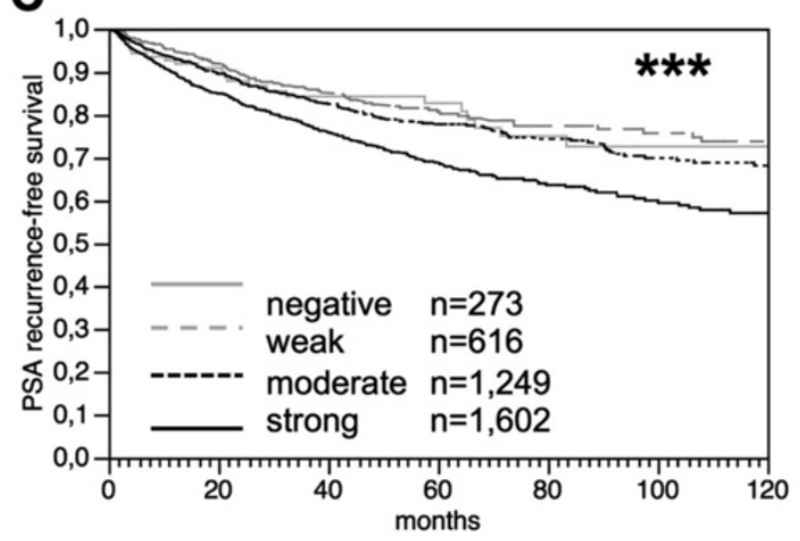

E

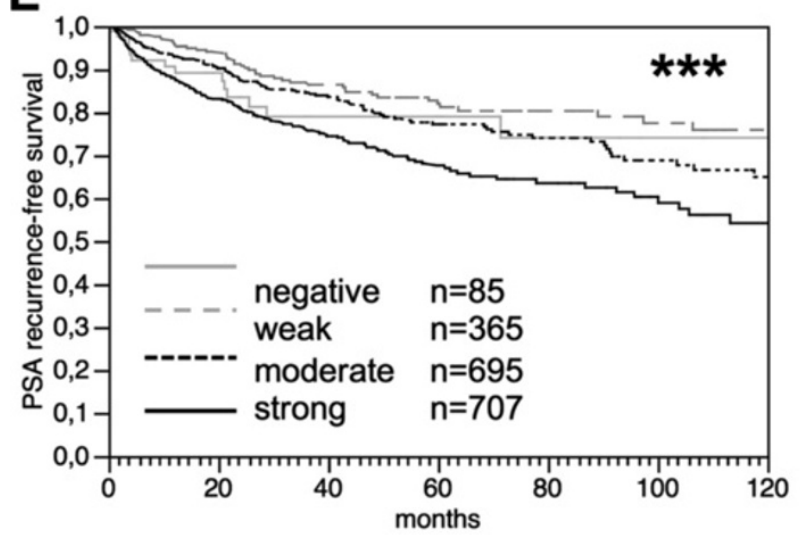

B

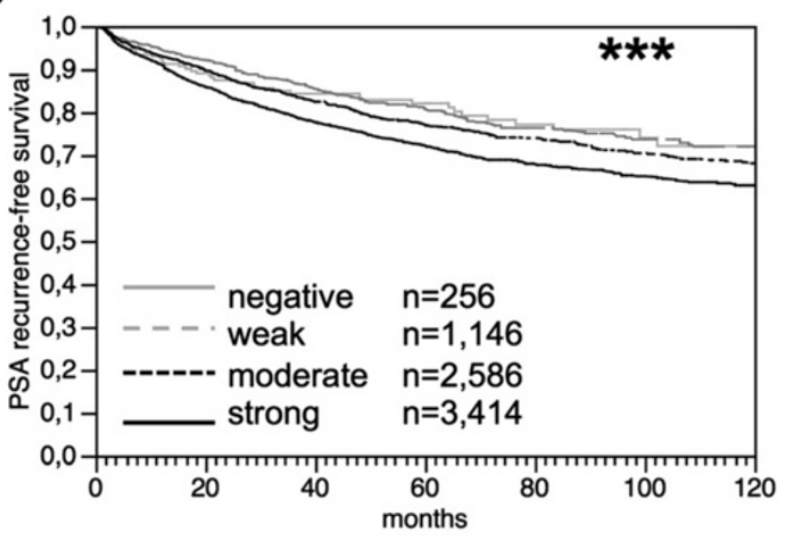

D

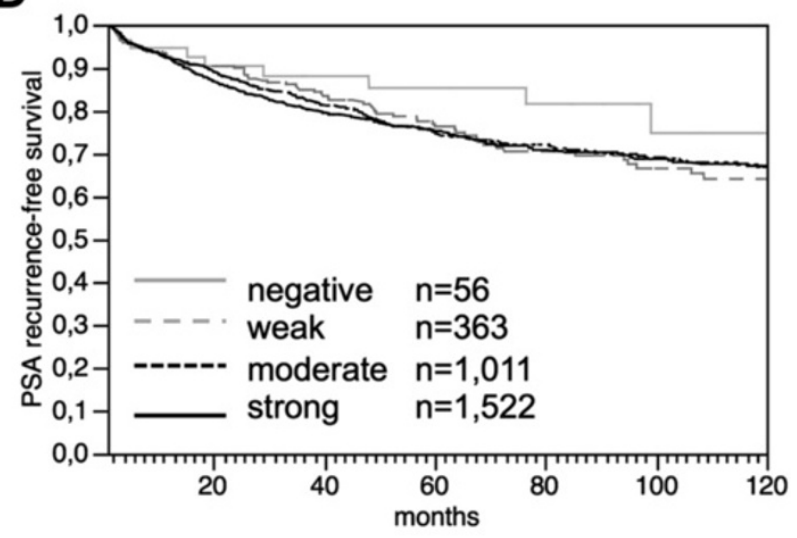

$\mathbf{F}$

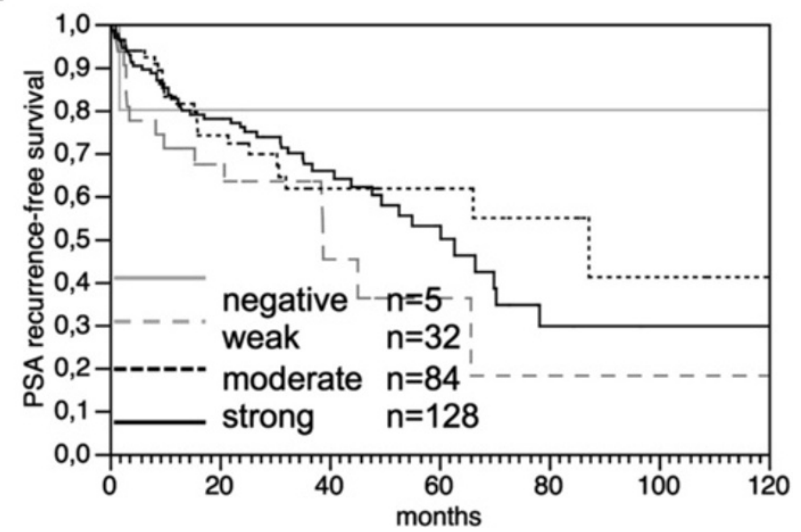

Figure 4 The prognostic impact of MTC02 expression in prostate cancer. The prognostic role of Gleason grade is given for this patient subset in order to demonstrate the overall validity of our follow-up data (***p $<0.0001$ ) (A). Association of MTC02 immunostaining with biochemical recurrence in (B) all prostate cancers ( $\left.{ }^{* * *} p<0.0001 ; n=7,402\right)$, (C) in the subset of ERG negative cancers $\left({ }^{* * *} p<0.0001 ; n=3,616\right)$, (D) in the subset of ERG positive cancers ( $p=0.7598 ; n=2,952)$, (E) ERG negative prostate cancers lacking PTEN deletions $(* * * p<0.0001 ; n=1,852)$, and (F) ERG negative prostate cancers harboring PTEN deletion $(p=0.2367 ; \mathrm{n}=249)$.

Immunohistochemical detection of a $60 \mathrm{KDa}$ nonglycosylated protein component of mitochondria was utilized in this project to quantitate mitochondria in cancer cells on TMAs. The TMA approach is optimal for the identification of subtle staining differences of proteins that are abundantly present in cancer, such as mitochondrial components, because TMAs enable maximal experimental standardization. In this study, more 
Table 4 Multivariate analysis including MTC02 expression status in (A) all cancers, (B) ERG negative and (C) ERG positive prostate cancers

\begin{tabular}{|c|c|c|c|c|c|c|c|c|}
\hline \multicolumn{9}{|l|}{ A } \\
\hline Scenario (n) & $\begin{array}{c}\text { preoperative } \\
\text { PSA-level }\end{array}$ & pT stage & cT stage & $\begin{array}{l}\text { Gleason grade } \\
\text { prostatectomy }\end{array}$ & $\begin{array}{c}\text { Biopsy } \\
\text { gleason grade }\end{array}$ & $\mathrm{N}$ status & R status & $\begin{array}{c}\text { MTC02 } \\
\text { expression }\end{array}$ \\
\hline $1(4,433)$ & $<0.0001$ & $<0.0001$ & & $<0.0001$ & & $<0.0001$ & $<0.0001$ & 0.656 \\
\hline $2(7,226)$ & $<0.0001$ & $<0.0001$ & & $<0.0001$ & & & $<0.0001$ & 0.8726 \\
\hline $3(7,078)$ & $<0.0001$ & & $<0.0001$ & $<0.0001$ & & & & 0.1282 \\
\hline $4(6,974)$ & $<0.0001$ & & $<0.0001$ & & $<0.0001$ & & & 0.0007 \\
\hline \multicolumn{9}{|l|}{ B } \\
\hline $1(2,220)$ & 0.0026 & $<0.0001$ & & $<0.0001$ & & $<0.0001$ & 0.0063 & 0.7664 \\
\hline $2(3,528)$ & $<0.0001$ & $<0.0001$ & & $<0.0001$ & & & 0.0002 & 0.8366 \\
\hline $3(3,489)$ & $<0.0001$ & & $<0.0001$ & $<0.0001$ & & & & 0.7614 \\
\hline $4(3,442)$ & $<0.0001$ & & $<0.0001$ & & $<0.0001$ & & & 0.0384 \\
\hline \multicolumn{9}{|l|}{$\bar{C}$} \\
\hline $1(1,791)$ & 0.0117 & $<0.0001$ & & $<0.0001$ & & 0.0118 & 0.003 & 0.7873 \\
\hline $2(2,884)$ & 0.0002 & $<0.0001$ & & $<0.0001$ & & & $<0.0001$ & 0.8902 \\
\hline $3(2,798)$ & $<0.0001$ & & $<0.0001$ & $<0.0001$ & & & & 0.2321 \\
\hline $4(2,752)$ & $<0.0001$ & & $<0.0001$ & & $<0.0001$ & & & 0.3955 \\
\hline
\end{tabular}

than 10,000 prostate cancer specimens were analyzed in one day in one experiment using one set of reagents at identical concentrations, temperatures and exposure times. Moreover, all TMA sections were cut on one day immediately before staining in order to avoid unequal decay of a tissues reactivity to antibody binding [37]. Finally, one pathologist interpreted all immunostainings at one day to enable maximal standardization of staining interpretation. In earlier studies, our TMA enabled us to validate several biomarkers with importance for prostate cancer, such as p53 expression [38], PTEN inactivation [32], CRISP3 overexpression [39] or deletions at $6 \mathrm{q} 15$ [31] and 5q21 [30].

The data derived from this approach demonstrate a marked increase of mitochondria content from normal prostate epithelial cells to cancer cells. A further increase was observed with increasing tumor grade and stage, suggesting that higher numbers of mitochondria are necessary or supportive for cancer development and progression. This is also supported by the observation that the mitochondrial content was linked to increased cell proliferation. Our findings are consistent with recent studies suggesting a prominent role of mitochondria content in cancer. For example, Ambrosini-Apaltro et al. [12] detected oncocytic, mitochondrion-rich modifications in adenocarcinoma cells after radiochemotherapy and Ragazzi et al. [26] described a link between mitochondrion-rich and undifferentiated breast cancers. Despite the early belief that cancer metabolism is primitive and inefficient, it has now become evident that cancer cells actively reprogram their metabolism activity [40]. Adaptation of cellular metabolism towards macromolecular synthesis is critical to supplying sufficient amounts of nucleotides, proteins, and lipids for cell growth and proliferation, which are fundamental to cell growth and proliferation [40]. Accordingly, previous studies described interactions between the mitochondrial metabolism and the activity of growth signaling pathways involving key human oncogenes such as Myc, Ras, Akt and phosphoinositide 3-kinase (Pi3K) [41-43]. Activated PI3K/Akt leads to enhanced glucose uptake and glycolysis $[44,45]$ by induction of glucose transporters, mitochondrial enzymes involved in the glycolytic metabolism and glucose carbon flux into biosynthetic pathways [46-49]. Downstream of PI3K/Akt, the well-characterized cell growth regulator mTORC1 also has many effects intertwined with mitochondrial metabolism [50-52]. Taken together, these findings demonstrate that the reprogramming of mitochondrial metabolism is a central aspect of PI3K/Akt associated oncogenic activity.

The large number of tumors analyzed in this study enabled us to separately analyze cancer subgroups defined by molecular features, the most common of which is the TMPRSS2:ERG gene fusion. Gene fusions involving the androgen-regulated gene TMPRSS2 and ERG, a member of the ETS family of transcription factors, occur in about $50 \%$ of prostate cancers, especially in young patients, and result in strong ERG protein overexpression [53-55]. Our data demonstrate that high mitochondrial content is significantly linked to fusion type prostate cancer. Finding this association by two independent approaches for ERG fusion detection (IHC/FISH) 
largely excludes a false positive association due to inefficient immunostaining for both MTC02 and ERG in a subset of damaged non-reactive tissues. This finding strongly argues for generally increased energy demands of ERG positive as compared to ERG negative cells. ERG expression causes massive deregulation of the global expression patterns in prostate cells. Several studies analyzing the transcriptomes of ERG positive and ERG negative tumors revealed that multiple energy-consumptive signaling pathways are activated as a result of ERG expression, including ER-, TGF- 3 , WNT, PI3K/Akt and Myc signaling [56-60] all of which involve multiple ATPases and ATP-dependent kinases. Particularly PI3K/ Akt and Myc signaling also directly activates glycolysis [43] and induces transcription of numerous glycolytic enzymes [4] in cancer cells.

That mitochondrial content has a different role and function in ERG positive and ERG negative cancers is further supported by our ERG-stratified analysis of disease outcome. Mitochondrial content had a prognostic role in ERG negative but not in ERG positive cancers. This striking difference may be caused by the substantial increase of cellular mitochondrial content by ERG rearrangements, which by themselves do not have any prognostic impact on prostate cancers. The magnitude of ERG-induced molecular and cellular changes, at least most of which are unrelated to cancer progression, may lead to an increased mitochondrial content in "fusiontype" prostate cancers, that masks demand for higher mitochondria content caused by specific molecular "progression events" requiring more mitochondrial function. The strong prognostic impact of mitochondria content in ERG negative prostate cancers fits well with models suggesting, that in a surrounding with low mitochondria content, "progression events" requiring more mitochondrial function would rather lead to a detectable increase of the mitochondria count, than in an environment with high mitochondria content.

Deletions of PTEN, 5q21 and 6q15 represent such "progression events" in prostate cancer as all of them are strongly linked to tumor growths and adverse clinical features. It seems likely that a shortage of nutrients and oxygen typically occurring during tumor expansion will eventually trigger additional adaptation steps, and increase of the mitochondrial content might be one of these. That such an increase of the mitochondrial content was not observed for 3p13 deletions may be due to the low number of analyzed ERG negative tumors for this deletion. Alternatively, it might be due to the small number of genes affected by these small 3p13 deletions, none of which may lead to additional "energy demand" in case of inactivation. A role of PTEN inactivation as a "progression event" associated with higher requirements for mitochondrial function is further supported by the observation that high mitochondrial content loses its prognostic relevance in PTEN deleted ERG negative cancers.

It is of note that the relationship between all analyzed deletions (PTEN, 3p13, 5q21, 6q15) and the mitochondria content tended to invert within ERG-positive cancers. The causes for this observation cannot be deducted from our data. It might be speculated, that non-vital ERG induced mitochondria production is restrained under a different cellular environment driving towards tumor progression including more rapid tumor cell growth. More specifically, it may be possible that specific molecular events caused by chromosomal deletions interfere with ERG induced general upregulation of number of mitochondria. It has indeed been shown, that PTEN inactivation can directly trigger both glycolysis [61] and mitochondrial respiratory capacity [62] through $\mathrm{AKT} / \mathrm{mTOR}$ signaling activation.

The marked prognostic relevance of mitochondrial abundance found in the subset of ERG negative cancers may suggest "mitochondria content" as a biomarker with potential clinical utility. This notion is further supported by the fact that the prognostic impact of mitochondria content was found on a TMA containing just one $0.6 \mathrm{~mm}$ cancer sample per patient. This approach of analyzing molecular features closely models the molecular analyses of core needle biopsies where comparable amounts of tissues are evaluated. Various models of multivariate analyses applied in this project indeed suggested an independent predictive role of mitochondria content for prognosis if only parameters were utilized that are available before radical prostatectomy. These data must be interpreted with caution, however, because the MTC02 immunostaining was done on tissue from radical prostatectomies and not on the core needle biopsies that were used to determine the preoperative Gleason grading. It is obvious, that potential prognostic biomarkers should be evaluated on preoperative needle biopsies but from a practical point of view such analyses are hardly feasible. This is because needle biopsies are usually done at many different facilities and not accessible for studies. Moreover, if such precious core needle biopsies were available, they would be exhausted after only few studies. Independent of this, it might be rewarding to further consider mitochondria content as a potential feature in multiparametric prognostic prostate cancer tests.

In summary, the results of our study highlight a different role of mitochondrial content in ERG fusion-positive and -negative cancers and identify "mitochondrial abundance" as a potential prognostic feature in ERG-negative cancers. Strong associations between chromosomal deletions and the cellular mitochondrial content further highlight the important role of mitochondria content as an adaptation process during cancer progression. 


\section{Competing interests}

The authors declare that they have no competing interest.

\section{Authors' contribution}

GS, TS, Jl, SS, RS and SM designed research; KG, KJ, MCT, CK, WW, AQ and MA performed the experiments and analyzed the data. GS, RS, KG, HH and MG wrote the manuscript. All authors read and approved the manuscript.

\section{Acknowledgements}

We thank Christina Koop, Julia Schumann, Sünje Seekamp, and Inge Brandt for excellent technical assistance.

\section{Author details}

${ }^{1}$ General, Visceral and Thoracic Surgery Department and Clinic, University Medical Center Hamburg-Eppendorf, Hamburg, Germany. ${ }^{2}$ Institute of Pathology, University Medical Center Hamburg-Eppendorf, Martinistr. 52, 20246 Hamburg, Germany. ${ }^{3}$ Martini-Clinic, Prostate Cancer Center, University Medical Center Hamburg-Eppendorf, Hamburg, Germany. ${ }^{4}$ Department of Urology, Section for translational Prostate Cancer Research, University Medical Center Hamburg-Eppendorf, Hamburg, Germany.

Received: 27 August 2013 Accepted: 15 November 2013 Published: 21 November 2013

\section{References}

1. Siegel R, Naishadham D, Jemal A: Cancer statistics, 2013. CA Cancer J Clin 2013, 63:11-30.

2. Haberland J, Bertz J, Wolf U, Ziese T, Kurth BM: German cancer statistics 2004. BMC Cancer 2010, 10:52.

3. Davis RE, Williams M: Mitochondrial function and dysfunction: an update J Pharmacol Exp Ther 2012, 342:598-607.

4. Fogg VC, Lanning NJ, Mackeigan JP: Mitochondria in cancer: at the crossroads of life and death. Chin J Cancer 2011, 30:526-539.

5. Abu-Amero KK, Alzahrani AS, Zou M, Shi Y: High frequency of somatic mitochondrial DNA mutations in human thyroid carcinomas and complex I respiratory defect in thyroid cancer cell lines. Oncogene 2005, 24:1455-1460.

6. Warowicka A, Kwasniewska A, Gozdzicka-Jozefiak A: Alterations in mtDNA: a qualitative and quantitative study associated with cervical cancer development. Gynecol Oncol 2013, 129:193-198.

7. Gao JY, Song BR, Peng JJ, Lu YM: Correlation between mitochondrial TRAP-1 expression and lymph node metastasis in colorectal cancer World J Gastroenterol 2012, 18:5965-5971.

8. Qian XL, Li YQ, Gu F, Liu FF, Li WD, Zhang XM, Fu L: Overexpression of ubiquitous mitochondrial creatine kinase (uMtCK) accelerates tumor growth by inhibiting apoptosis of breast cancer cells and is associated with a poor prognosis in breast cancer patients. Biochem Biophys Res Commun 2012, 427:60-66.

9. Gogvadze V, Orrenius S, Zhivotovsky B: Mitochondria as targets for cancer chemotherapy. Semin Cancer Biol 2009, 19:57-66.

10. Leber B, Geng F, Kale J, Andrews DW: Drugs targeting Bcl-2 family members as an emerging strategy in cancer. Expert Rev Mol Med 2010, 12:e28. 10.1017/S1462399410001572.

11. Indran IR, Tufo G, Pervaiz S, Brenner C: Recent advances in apoptosis, mitochondria and drug resistance in cancer cells. Biochimica Et Biophysica Acta-Bioenergetics 1807, 2011:735-745.

12. Ambrosini-Spaltro A, Salvi F, Betts CM, Frezza GP, Piemontese A, Del Prete $P$, Baldoni C, Foschini MP, Viale G: Oncocytic modifications in rectal adenocarcinomas after radio and chemotherapy. Virchows Arch 2006, 448:442-448.

13. Geyer FC, de Biase D, Lambros MB, Ragazzi M, Lopez-Garcia MA, Natrajan R, Mackay A, Kurelac I, Gasparre G, Ashworth A, et al: Genomic profiling of mitochondrion-rich breast carcinoma: chromosomal changes may be relevant for mitochondria accumulation and tumour biology. Breast Cancer Res Treat 2012, 132:15-28.

14. Chen JZ, Gokden N, Greene GF, Mukunyadzi P, Kadlubar FF: Extensive somatic mitochondrial mutations in primary prostate cancer using laser capture microdissection. Cancer Res 2002, 62:6470-6474.

15. Chen JZ, Kadlubar FF: Mitochondrial mutagenesis and oxidative stress in human prostate cancer. J Environ Sci Health C Environ Carcinog Ecotoxicol Rev 2004, 22:1-12
16. Jeronimo C, Nomoto S, Caballero OL, Usadel H, Henrique R, Varzim G, Oliveira J, Lopes C, Fliss MS, Sidransky D: Mitochondrial mutations in early stage prostate cancer and bodily fluids. Oncogene 2001, 20:5195-5198.

17. Jessie BC, Sun CQ, Irons HR, Marshall FF, Wallace DC, Petros JA: Accumulation of mitochondrial DNA deletions in the malignant prostate of patients of different ages. Exp Gerontol 2001, 37:169-174.

18. Kloss-Brandstatter A, Schafer G, Erhart G, Huttenhofer A, Coassin S, Seifarth C, Summerer M, Bektic J, Klocker H, Kronenberg F: Somatic mutations throughout the entire mitochondrial genome are associated with elevated PSA levels in prostate cancer patients. Am J Hum Genet 2010, 87:802-812

19. Lindberg J, Mills IG, Klevebring D, Liu W, Neiman M, Xu J, Wikstrom P, Wiklund P, Wiklund F, Egevad L, Gronberg H: The mitochondrial and autosomal mutation landscapes of prostate cancer. Eur Urol 2013, 63:702-708

20. Parr RL, Dakubo GD, Crandall KA, Maki J, Reguly B, Aguirre A, Wittock R, Robinson K, Alexander JS, Birch-Machin MA, et al: Somatic mitochondrial DNA mutations in prostate cancer and normal appearing adjacent glands in comparison to age-matched prostate samples without malignant histology. J Mol Diagn 2006, 8:312-319.

21. Petros JA, Baumann AK, Ruiz-Pesini E, Amin MB, Sun CQ, Hall J, Lim S, Issa MM, Flanders WD, Hosseini SH, et al: mtDNA mutations increase tumorigenicity in prostate cancer. Proc Natl Acad Sci USA 2005, 102:719-724.

22. Yu JJ, Yan T: Effect of mtDNA mutation on tumor malignant degree in patients with prostate cancer. Aging Male 2010, 13:159-165.

23. Leav I, Plescia J, Goel HL, Li J, Jiang Z, Cohen RJ, Languino LR, Altieri DC: Cytoprotective Mitochondrial Chaperone TRAP-1 As a Novel Molecular Target in Localized and Metastatic Prostate Cancer. Am J Pathol 2010, 176:393-401.

24. Altieri DC, Languino $L R$, Lian JB, Stein $J$, Leav I, van Wijnen AJ, Jiang $Z$, Stein GS: Prostate cancer regulatory networks. J Cell Biochem 2009, 107:845-852.

25. de Bari L, Moro L, Passarella S: Prostate cancer cells metabolize d-lactate inside mitochondria via a D-lactate dehydrogenase which is more active and highly expressed than in normal cells. FEBS Lett 2013, 587:467-473.

26. Ragazzi M, de Biase D, Betts CM, Farnedi A, Ramadan SS, Tallini G, Reis-Filho JS, Eusebi V: Oncocytic carcinoma of the breast: frequency, morphology and follow-up. Hum Pathol 2011, 42:166-175.

27. Erbersdobler A, Fritz H, Schnoger S, Graefen M, Hammerer P, Huland $H$, Henke RP: Tumour grade, proliferation, apoptosis, microvessel density, p53, and bcl-2 in prostate cancers: differences between tumours located in the transition zone and in the peripheral zone. Eur Urol 2002, 41:40-46.

28. Mirlacher M, Simon R: Recipient block TMA technique. Methods Mol Biol 2010, 664:37-44.

29. Minner S, Enodien M, Sirma H, Luebke AM, Krohn A, Mayer PS, Simon R, Tennstedt $P$, Muller J, Scholz $L$, et al: ERG status is unrelated to PSA recurrence in radically operated prostate cancer in the absence of antihormonal therapy. Clin Cancer Res 2011, 17:5878-5888.

30. Burkhardt L, Fuchs S, Krohn A, Masser S, Mader M, Kluth M, Bachmann F, Huland H, Steuber T, Graefen M, et al: CHD1 Is a $5 q 21$ tumor suppressor required for ERG rearrangement in prostate cancer. Cancer Res 2013, 73:2795-2805.

31. Kluth M, Hesse J, Heinl A, Krohn A, Steurer S, Sirma H, Simon R, Mayer PS, Schumacher U, Grupp K, et al: Genomic deletion of MAP3K7 at 6q12-22 is associated with early PSA recurrence in prostate cancer and absence of TMPRSS2:ERG fusions. Mod Pathol 2013, 26:975-983.

32. Krohn A, Diedler T, Burkhardt L, Mayer PS, De Silva C, Meyer-Kornblum M, Kotschau D, Tennstedt P, Huang J, Gerhauser C, et al: Genomic deletion of PTEN is associated with tumor progression and early PSA recurrence in ERG fusion-positive and fusion-negative prostate cancer. Am J Pathol 2012, 181:401-412

33. Bubendorf $L$, Sauter $G$, Moch $H$, Schmid HP, Gasser TC, Jordan $P$, Mihatsch MJ: Ki67 labelling index: an independent predictor of progression in prostate cancer treated by radical prostatectomy. J Pathol 1996, 178:437-441.

34. Berger MF, Lawrence MS, Demichelis F, Drier $Y$, Cibulskis $K_{1}$ Sivachenko AY, Sboner A, Esgueva R, Pflueger D, Sougnez C, et al: The genomic complexity of primary human prostate cancer. Nature 2011, 470:214-220. 
35. Lapointe J, Li C, Giacomini CP, Salari K, Huang S, Wang P, Ferrari M, Hernandez-Boussard T, Brooks JD, Pollack JR: Genomic profiling reveals alternative genetic pathways of prostate tumorigenesis. Cancer Res 2007 67:8504-8510.

36. Taylor BS, Schultz N, Hieronymus H, Gopalan A, Xiao Y, Carver BS, Arora VK, Kaushik P, Cerami E, Reva B, et al: Integrative genomic profiling of human prostate cancer. Cancer Cell 2010, 18:11-22.

37. Simon R, Mirlacher M, Sauter G: Immunohistochemical analysis of tissue microarrays. Methods Mol Biol 2010, 664:113-126.

38. Schlomm $T$, Iwers $L$, Kirstein $P$, Jessen B, Kollermann J, Minner $S$, Passow-Drolet A, Mirlacher M, Milde-Langosch K, Graefen M, et al: Clinical significance of p53 alterations in surgically treated prostate cancers. Mod Pathol 2008, 21:1371-1378.

39. Grupp K, Kohl S, Sirma H, Simon R, Steurer S, Becker A, Adam M, Izbicki J, Sauter G, Minner $S$, et al: Cysteine-rich secretory protein 3 overexpression is linked to a subset of PTEN-deleted ERG fusion-positive prostate cancers with early biochemical recurrence. Mod Pathol 2013, 26:733-742.

40. Ward PS, Thompson CB: Metabolic reprogramming: a cancer hallmark even warburg did not anticipate. Cancer Cell 2012, 21:297-308.

41. Hsu PP, Sabatini DM: Cancer cell metabolism: Warburg and beyond. Cell 2008, 134:703-707.

42. Jones RG, Thompson CB: Tumor suppressors and cell metabolism: a recipe for cancer growth. Genes Dev 2009, 23:537-548.

43. Levine AJ, Puzio-Kuter AM: The control of the metabolic switch in cancers by oncogenes and tumor suppressor genes. Science 2010, 330:1340-1344.

44. Buzzai M, Bauer DE, Jones RG, Deberardinis RJ, Hatzivassiliou G, Elstrom RL, Thompson CB: The glucose dependence of Akt-transformed cells can be reversed by pharmacologic activation of fatty acid beta-oxidation. Oncogene 2005, 24:4165-4173.

45. Elstrom RL, Bauer DE, Buzzai M, Karnauskas R, Harris MH, Plas DR, Zhuang $H$, Cinalli RM, Alavi A, Rudin CM, Thompson CB: Akt stimulates aerobic glycolysis in cancer cells. Cancer Res 2004, 64:3892-3899.

46. Deprez J, Vertommen D, Alessi DR, Hue L, Rider MH: Phosphorylation and activation of heart 6-phosphofructo-2-kinase by protein kinase $B$ and other protein kinases of the insulin signaling cascades. J Biol Chem 1997, 272:17269-17275.

47. Gottlob K, Majewski N, Kennedy S, Kandel E, Robey RB, Hay N: Inhibition of early apoptotic events by Akt/PKB is dependent on the first committed step of glycolysis and mitochondrial hexokinase. Genes Dev 2001, 15:1406-1418.

48. Kohn AD, Summers SA, Birnbaum MJ, Roth RA: Expression of a constitutively active Akt Ser/Thr kinase in 3T3-L1 adipocytes stimulates glucose uptake and glucose transporter 4 translocation. J Biol Chem 1996, 271:31372-31378

49. Wakil SJ, Porter JW, Gibson DM: Studies on the mechanism of fatty acid synthesis. I. Preparation and purification of an enzymes system for reconstruction of fatty acid synthesis. Biochim Biophys Acta 1957, 24:453-461.

50. Bentzinger CF, Romanino K, Cloetta D, Lin S, Mascarenhas JB, Oliveri F, Xia J, Casanova E, Costa CF, Brink M, et al: Skeletal muscle-specific ablation of raptor, but not of rictor, causes metabolic changes and results in muscle dystrophy. Cell Metab 2008, 8:411-424.

51. Cunningham JT, Rodgers JT, Arlow DH, Vazquez F, Mootha VK Puigserver P: mTOR controls mitochondrial oxidative function through a YY1-PGC-1alpha transcriptional complex. Nature 2007, 450:736-740.

52. Schieke SM, Phillips D, McCoy JP Jr, Aponte AM, Shen RF, Balaban RS, Finkel T: The mammalian target of rapamycin (mTOR) pathway regulates mitochondrial oxygen consumption and oxidative capacity. J Biol Chem 2006, 281:27643-27652.

53. Weischenfeldt J, Simon R, Feuerbach L, Schlangen K, Weichenhan D, Minner S, Wuttig D, Warnatz HJ, Stehr H, Rausch T, et al: Integrative genomic analyses reveal an androgen-driven somatic alteration landscape in early-onset prostate cancer. Cancer Cell 2013, 23:159-170.

54. Tomlins SA, Rhodes DR, Perner S, Dhanasekaran SM, Mehra R, Sun XW, Varambally S, Cao X, Tchinda J, Kuefer R, et al: Recurrent fusion of TMPRSS2 and ETS transcription factor genes in prostate cancer. Science 2005, 310:644-648.

55. Tomlins SA, Mehra R, Rhodes DR, Smith LR, Roulston D, Helgeson BE, Cao X, Wei JT, Rubin MA, Shah RB, Chinnaiyan AM: TMPRSS2:ETV4 gene fusions define a third molecular subtype of prostate cancer. Cancer Res 2006, 66:3396-3400.
56. Brase JC, Johannes M, Mannsperger H, Falth M, Metzger J, Kacprzyk LA, Andrasiuk T, Gade S, Meister M, Sirma H, et al: TMPRSS2-ERG -specific transcriptional modulation is associated with prostate cancer biomarkers and TGF-beta signaling. BMC Cancer 2011, 11:507.

57. Gupta S, Iljin K, Sara H, Mpindi JP, Mirtti T, Vainio P, Rantala J, Alanen K, Nees M, Kallioniemi O: FZD4 as a mediator of ERG oncogene-induced WNT signaling and epithelial-to-mesenchymal transition in human prostate cancer cells. Cancer Res 2010, 70:6735-6745.

58. Jhavar S, Brewer D, Edwards S, Kote-Jarai Z, Attard G, Clark J, Flohr P, Christmas T, Thompson A, Parker M, et al: Integration of ERG gene mapping and gene-expression profiling identifies distinct categories of human prostate cancer. BJU Int 2009, 103:1256-1269.

59. Hawksworth D, Ravindranath $L$, Chen $Y$, Furusato B, Sesterhenn IA McLeod DG, Srivastava S, Petrovics G: Overexpression of C-MYC oncogene in prostate cancer predicts biochemical recurrence. Prostate Cancer Prostatic Dis 2010, 13:311-315.

60. Zong Y, Xin L, Goldstein AS, Lawson DA, Teitell MA, Witte ON: ETS family transcription factors collaborate with alternative signaling pathways to induce carcinoma from adult murine prostate cells. Proc Natl Acad Sci USA 2009, 106:12465-12470.

61. Manning BD, Cantley LC: AKT/PKB signaling: navigating downstream Cell 2007, 129:1261-1274

62. Goo CK, Lim HY, Ho QS, Too HP, Clement MV, Wong KP: PTEN/Akt signaling controls mitochondrial respiratory capacity through 4E-BP1. PLoS One 2012, 7:e45806.

\section{doi:10.1186/1476-4598-12-145}

Cite this article as: Grupp et al:: High mitochondria content is associated with prostate cancer disease progression. Molecular Cancer 2013 12:145.

\section{Submit your next manuscript to BioMed Central and take full advantage of:}

- Convenient online submission

- Thorough peer review

- No space constraints or color figure charges

- Immediate publication on acceptance

- Inclusion in PubMed, CAS, Scopus and Google Scholar

- Research which is freely available for redistribution 